\title{
Puzzling about problems: the ambiguous search for an evidence-based strategy for handling influx of health technology
}

Ann-Charlotte Nedlund and Peter Garpenby

\author{
Linköping University Post Print
}

Tweet

N.B.: When citing this work, cite the original article.

The original publication is available at www.springerlink.com:

Ann-Charlotte Nedlund and Peter Garpenby, Puzzling about problems: the ambiguous search for an evidence-based strategy for handling influx of health technology, 2014, Policy sciences, (47), 4, 367-386.

http://dx.doi.org/10.1007/s11077-014-9198-1

Copyright: Springer Verlag (Germany)

http://www.springerlink.com/?MUD=MP

Postprint available at: Linköping University Electronic Press

http://urn.kb.se/resolve?urn=urn:nbn:se:liu:diva-108717 
Ann-Charlotte Nedlund, PhD, Division of Health Care Analysis, Department of Medical and Health Sciences, Linköping University, 58183 Linköping, Sweden

e-mail: ann-charlotte.nedlund@liu.se

Peter Garpenby, PhD, Division of Health Care Analysis, Department of Medical and Health Sciences, Linköping University, 58183 Linköping, Sweden

\section{Abstract}

This paper focuses on problem frame differences among actors (members of an advisory body, senior administrators and clinical unit managers) who are concerned with the introduction of new health technology at the regional level in Sweden. It explores issues related to problem framing, puzzling, powering, participation and the various rationales articulated in the ambiguous search for an evidence-based strategy to handle the influx of new technologies. The Health Technology Advisory Committee (HTAC) was established in one Swedish county council in 2004 with the intention of controlling both the introduction of health technology and supporting policy decision and clinical practice by promoting the use of best evidence. The HTAC followed a scientific rationality dominated by one problem frame, although the problematic situation, as it was framed by all the actor groups, was highly complex and not solely a matter of evidence. This paper illustrates how problem frame differences shape the puzzling of a policy problem and how the different distinguishable policy styles are dependent on who is participating and who is not participating in the puzzling.

Keywords: Evidence-based policy, Problem frames, Policy practice, Policy style, Health technology, Sweden 


\section{Introduction}

Healthcare is one of the most knowledge-intensive sectors where innovations are continuously put into practice. Innovations in the form of products and methods originate from research and development, a growing part of which is initiated by commercial actors (Moran 1995). Today the strong influx of health technology puts increased strain on the healthcare system and its various decision-makers. A dilemma that has fostered a way of thinking where the strengthening of the scientific base in organisational practice is regarded as the key to "good patient care" and implies that policy in this field is a technical course of action. Within the prominent discourse of "best evidence", the underlying thought is that policies are value-free, and should be generated by facts, and that these entities can be clearly separated. Hence, evidence is regarded as context free and something that can be classified and weighted (Russell et al. 2008). In this rationalistic view, the policy process is about sorting out what is the best evidence, deciding upon it and implementing what is decided. If implementation should "fail", either the policy has to be improved by reassessing what is the best evidence or barriers have to be overcome before the best practice can be achieved. Therefore, there are strong tendencies to search for "the technocratic fix" in the health policy arena (Syrett 2003).

The aim of this paper was to shed light on how problem frame differences on evidencebased policy (EBP) in a regional healthcare context, shape the puzzling over how to handle the influx of new technologies. Furthermore, we intend to show that depending on institutional norms, different features are selected for attention in a particular context, resulting in various modes of operation; i.e. policy styles. We use an example in one Swedish county council (CC), where a specific working group was created to handle and control new technologies, the Health Technology Advisory Committee (HTAC). The paper draws on the concepts of problem frames (Scho“n and Rein 1994), puzzling, powering and participation (Heclo 1974/2010; Hoppe 2010), and the competing rationalities (Lin 2003) that are articulated in an ambiguous search for an evidence-based strategy.

The case serves as an example of the practical tension between problem finding and problem solving, how problems are puzzled, how they relate to various institutionalised rationales for action, and the location of power when enacting and practicing evidence in policy. This study contributes to the theoretical debate on how policies take shape in complex knowledgeintensive policy fields with various problem frames. 


\section{Brief background to the HTAC}

Sweden is among those countries generally considered to be extensive users of health technology with high regular uptake of innovations in the field of healthcare, although the diffusion varies considerably between the different technologies (Packer et al. 2006). Influenced by international initiatives in health technology assessment (HTA), evidencebased medicine (EBM) and "scientific advice" (Bijker et al. 2009), activities pointing in the direction of management by knowledge are discernible in several bodies at national level, performing assessment studies and systematic reviews of evidence on health technologies and providing recommendations to decision-makers at national and regional levels. Two of the most prominent examples of this trend in Sweden are the recommendations by the Swedish Council on Technology Assessment in Health Care (SBU) and the National Guidelines issued by the National Board of Health and Welfare (NBHW). At the important regional level, where the directly elected CCs provide publicly funded health services to the population, the first advisory boards on health technology were set-up only 10 years ago. They are still not very common at regional level, but where they do exist they are usually responsible for gathering evidence-based data on particular health technologies, with the intention of advising both political decision-makers and medical management.

The HTAC was established in 2004 in one CC as an advisory body on health technology (although a separate advisory body already existed for pharmaceuticals, HTAC could occasionally examine new drugs). From the beginning, HTAC had a somewhat ambiguous role within the $\mathrm{CC}$ decision-making structure on health technology. It states, in the instruction for HTAC, that the body, on the one hand, "should facilitate the introduction of promising and efficient technologies, while those that were considered controversial or had an uncertain medical effect and/or cost-efficiency, should be prohibited from dissemination" (CCO 2011). On the other hand, this body was assigned to purely supporting and advising the clinical units and had no discretion to decide on the investment or disinvestment of a particular technology. These decisions were expected to be taken within the formal structure for commission and priority setting in the $\mathrm{CC}$; i.e. as a negotiation between the political and administrative branch on one side and the clinical branch (the clinical units and the clinical centres representing a group of units) on the other. In the instruction, it was never stated exactly what criteria HTAC should use when examining a technology, but examples such as medical effect, costefficiency, patient benefit, side effects, economic and/or organisational consequences for the health service and ethical aspects were mentioned. 
In 2008, the membership was extended to 15 and on that occasion, a core group of five members with extensive experience of healthcare and with different strategic backgrounds (clinical research, health economics, pharmaceuticals, etc.) was formed. The core group was required to prepare new items to be passed on to the extended HTAC, made up of various experts from clinical practice (commonly unit managers) and from the ethical committee in the $\mathrm{CC}$, which was occasionally called in to discuss specific cases. The members in the extended group could also be called in if a case needed specific expertise when evaluating health technology.

\section{Theorising health technology as a policy problem}

Efforts to regulate the use of technology in the health sector can take various forms, such as approval of drugs, pricing control, reimbursement systems, and more prominent in latter decades, dissemination of results from HTA, and cost-utility studies condensed into recommendations or guidelines. What these initiatives have in common is a strong belief that scientific evidence should underpin public policy. Thus, they could be regarded as examples of EBP.

The wish for EBP is, however, commonly based on a simplified view of the nature of policy. In health policy, various and competing types of rationality can be identified; scientific, which is dominated by positivist science; political, which relates to the distribution and management of power; and cultural, which refers to the norms and expectations in society (Lin 2003; cf. Lehoux et al. 2010). These competing rationalities are commonly presented by their advocates as "truths". Therefore, the concept of EBP and its implicit desire for uniform rationality is in many ways ambiguous. Moreover, EBP is elusive since the evidence in itself is ambiguous; what is meant by evidence is always dependent on the specific account, e.g. as decontextualising, as in the case of the EBP or as contextualising by reason giving as often done by politicians (Lin 2003). In EBP, evidence and knowledge are commonly seen as separate from practice. However, in our view, knowledge comes about through practice and cannot be separated from it (Freeman 2007). Hence, evidence can be both the means and the goal (Lin 2003). Evidence is important in the negotiation of ideas, it is "information selected from the available stock and introduced at a specific point in the argument, in order to persuade a 
particular audience of the truth or falsity of a statement" (Majone 1989:10). Hence, the relationship between policy and evidence is not only dynamic but also highly ambiguous.

Those advocating EBP tends to disregard that policy is a process where people with social roles, and not abstractions of actors, are interacting and negotiating ideas and values (Stone 2002; Schneider and Ingram 1997) in an attempt to come to shared understandings of how to handle collective concern appropriately (Colebatch 2006; Nedlund 2012). A policy problem is not just "there", it does not follow pure rationality and it is often constructed before the goals are formulated, or after an identified solution. Both the means and the goals are subject to discussion. Policy problems are socially constructed in a process of collective definition (Blumer 1971; Stone 2002; Klein 2003; Greenhalgh and Russell 2009). Moreover, the construction of problems is an on-going process. One way is, as in Turnbull (2013), to understand it as a questioning process where a political phenomenon may on one occasion appear as non-problematic, when the questioning is forgotten as a result of strong forms of answering and solutions. On another occasion, it may appear as problematic, when there are weak forms of answering, which re-confirm the questioning and maintain the phenomenon as problematic. What is emphasised by Turnbull is that problems and practice are the defining characters of policy orientation. He argues that there is a need to focus on the questioning process and, in line with Hoppe (2010) the problem structuring, instead of the problem solving that is commonly studied. In order to theorise health technology and the efforts to regulate its use through bodies such as the HTAC, we will see it as related to questioning and answering and problem structuring.

Schön and Rein (1994) understand the constructions of policy problems and preferred solutions to be based on different problem frames. These frames, i.e. underlying structures of belief, perception and appreciation, are shaping policy positions. In a policy controversy, opposing actors have different stories and thus different views of reality. They hold conflicting frames, which determine what facts are "true', what arguments are relevant. Problem framing is about selecting and also simplifying vague or complex problematic situations. In ambiguous and complex situations, actors create stories of social reality through a complementary process of naming and framing, where different features from a particular context are selected for attention. According to Schön and Rein, the naming and framing carries out the essential problem-setting function by identifying what is wrong and by setting the direction for its future transformation, a process wherein the stories of the policy workers 
make a "normative leap" from "what is" to "what ought to be". Schön and Rein's notion of frames is relevant in order to understand the shaping of policy and its variety of problem frames.

Accordingly, each policy worker or collective, through sense-making (Weick 1995; Colebatch 2011; Noordegraaf 2010; Nedlund 2012), is capable of alternative interpretations, i.e. problem frames, of both problems and their potential solutions (Turnbull 2013). In practice, construction of problems "is enacted through a highly complex and variable process involving many different lines of questioning by many different individual questioners in many different domains of practice. Individuals confront problems as they appear for them, in the context of their policy work, which itself goes towards constructing what we know as 'policy problems',' (Turnbull 2013:122). It has to be emphasised, as we understand it, that the problem frames that policy workers use are dependent on the interaction with others (Dewulf et al. 2005) when policy workers are grasping for what to do in the specific situation at hand (Wagenaar 2004). Thus, problem frames have to be understood not only in relation to the single individual, but also to the individual sensemaking with others in a particular institutional context.

The existence of a variety of problem frames shapes policies through a process of "puzzling, powering and participation' (Hoppe 2010). From this account of approaching policy problems, policy is a process of "collective puzzling" (Heclo 1974/2010) to understand what the problem is and to find feasible courses of action related to practice in times of uncertainty and disagreement; a situation most common to policy making. Thereare of course mixed forms of problems with greater or lesser uncertainties (Hisschemöller and Hoppe 1996; Hoppe 2010; Wesselink and Hoppe 2011; Bijker et al. 2009). The puzzling process can be related both to uncertainty of knowledge, i.e. between knowing and not-knowing within a certain frame, and to ambiguity of the meaning of a situation and what frame to apply to make sense of it, i.e. between different frames of knowing (Dewulf et al. 2005; Hoppe 2010).

When applied to the collective activity of politics, the dimension of power plays an important role in enacting what are constructed as problems and their resolutions (Turnbull 2013:119). However, to Heclo, power was not the sole factor for determining the content of policy. Rather, in his view, decision-makers do not just "power", as the element of "collective puzzlement"' is equally, if not more important for the substance of policy. 
Hall (1993), when examining the change of macroeconomic policy in Britain, noticed that "powering" and "puzzling" were often intertwined. Collective actors whether political parties, organised interests or policy experts, acquire power to get access to - participate inthe setting where policies are shaped. To be part of the "collective puzzlement" is to influence the "political discourse", whereby the context for contemporary political developments is settled and thus how the issues at hand are to be understood (Hall 1993:289). Visser and Hemerijck (1997), drawing on Heclo (1974/2010) and in particular on Hall (1993), recognise the importance of "puzzling" and "powering" for policy change. Major changes of policy - what Hall called paradigmatic change-require a shift in the understanding of the policy problem. Usually, the alteration of policy takes place within closed policy networks among the policy elites - where actors position themselves - "powering" - in order to participate in the "puzzling" over the problem. Radical change, where the problem is understood in a new way, often emanates from outwith the policy elite, where social and political debate flourishes more freely, after which the issue can move into established frameworks to be institutionalised (Visser and Hemerijck 1997:78).

Puzzling is also dependent on how power is distributed among the members in a current policy network, i.e. the person who is allowed to participate in the puzzling of knowledge in the policy network is what matters. According to Hoppe, this is a central component. This implies that those in power can define what is regarded as rationality and knowledge. Moreover, problem structuring can be dominated by one puzzling style, which becomes hegemonic and limits alternatives. The component of power can never be neglected since it defines what is regarded as a "rational" knowledge or the normative truth: "when we make claims about facts, we appeal for the consent of others in terms such as what is "good" science" (Hoppe 2010:68). Therefore, behind the simplest definition of a problem lies a complex social construction that expresses not only facts, but also values.

In a recent study, Vink et al. (2012) examine how the interplay between "puzzling" over problems and "powering" over interests are linked to the concept of problem framing. Using examples from environmental issues, the study tentatively shows how the process of puzzling over appropriate problem frames can be used in the reallocation of power. Hence, when powering appears as a means to participate in puzzling, resulting in the reordering of power, 
this is a neat illustration of what Heclo and Hall once observed that the two concepts are closely interwoven.

We chose to study problem frames since they may indicate differences in policy positions that could have vital implications in a particular social context and for the shaping of policy. Actors will not usually question dispositions in the treatment of practical problems that are within the practical actions of what they do and how they relate to each other. As explained by Turnbull (2013:124), actors "want a solution to the problem, but one to which they already "know" how to respond through their own practice and understand their strategic political goals"'. As he points out, this is related to how strong the questioning and answering is, as well as the legitimation of the actors' own positions in their particular field (whether political, bureaucratic, managerial, professional, etc.).

According to Hisschemo“" ller and Hoppe (1996), policy makers at senior levels often prefer to see problems as a jigsaw puzzle where there is only one solution, i.e. each piece has its given place, as this minimises their uncertainty and restricts the solutions to already existing practices. In other words, the problem becomes or seems to become a doable. Hence, the different problem frames are seldom discussed or reflected upon. Depending on this lack of awareness, there is always a risk that the wrong problem is handled, i.e. a wrong problem problem. This should not be regarded as an intellectual mistake, however, but rather a situation occurring because it is regarded as a rational solution (rationality of power). Hence, there can be tensions between what are regarded as problematic situations (problem finding) and what are regarded as solutions (problem solving).

Moreover, as explained by Rein and Scho“n (1996:156), the framing of a policy issue always takes place in a specific institutional context that may carry its own characteristics and ways of framing issues and may offer particular roles, channels and norms for discussion and debate. In such a context, the institutional framing of a problem and its immanent solution often develop into what can, according to our view, be named policy styles. This concept is used here to refer to the modes of operation that result from the different ways of puzzling and powering problems. A policy style can be regarded as a particular approach, logic or process that is institutionalised, though it need not be the "standard operating procedure" present at the scene (in contrast to the way this concept is commonly used; see e.g. Richardson et al. 1982; Howlett 2002). Hence, there can be different policy styles present at 
the same time since similar problematic situations can be puzzled in different ways in the same setting. Furthermore, a policy style need not be static or a long-term set pattern, but can be dynamic and diversely distinct over time. In line with Rein and Schön's reasoning on framing, we understand that a particular policy style can be formed by institutionalised norms for discussions and debate. For instance, a specific policy style can be formed by norms of an evidence-based rationale. Furthermore, the framing tends to conform to the norms of the institution in which it is embedded (Rein and Schön 1996:156). Thus, policy styles are related to the way problems are framed and to the institutionalised norms in the specific context.

Drawing on the theoretical perspectives outlined above, we will examine the variety of problem frames among four actor groups and how the puzzling and powering relate to different policy styles.

\section{Methodology}

A qualitative case study was designed and conducted. During the period June to December 2011, a single episode interview study was conducted in one CC in Sweden. Four categories of actors were recruited for the study: senior administrators; members of the HTAC core group; members in the extended HTAC; clinical unit managers. Since the point of departure was the existence of the HTAC, we decided to select actors with experience from within the body (members of the HTAC core group; members in the extended HTAC). They had been appointed to carry out the task of making HTAC an important tool for the control of health technologies within the $\mathrm{CC}$, as they were considered to be experts in this area. As HTAC had been set-up to support and advise above all the clinical units, managers from that level of the $\mathrm{CC}$ ought to be included; they could be expected to have major experience of the role of technology at the clinical level, although not all of them had collaborated directly with HTAC. Although HTAC should support the clinical level, it had been commissioned from the top of the $\mathrm{CC}$, where the perception of the current policy issue among senior administrators was important, as they had the role of advising the regional politicians on this issue, e.g. the conception of the policy problem and possible solutions. Hence, the intention was not to pinpoint problem frames on the use of health technology in general; therefore, no patient groups, etc., were included. 
All members of the HTAC core group were interviewed, as they were prime key informants. The sampling of the extended HTAC and the unit mangers was stratified; in the first case according to background (clinical, academic and as ethicists), and in the latter to include informants from (a) the three different geographical areas of the CC (east, central, west) and (b) from a wide spectrum of units in the $\mathrm{CC}$ (primary healthcare, rehabilitation, diagnostic services, gynaecology and obstetrics, internal medicine, general surgery, neurosurgery and cardiology). The sampling of the senior administrators was strategic (Patton 2002); they were considered to have key positions in advising the politicians on the issue. Nineteen semistructured open-ended interviews were conducted by one of the authors (ACN): senior administrators (3); members in the HTAC core group (5); members in the extended HTAC (3); unit mangers (8).

Interviews were considered the most appropriate way to collect data for two reasons: First, face-to-face interviewing is preferable as the language used by participants is essential to gain insight into their perceptions and values (Gillman 2000; Ritchie and Lewis 2003). Second, although problem framing is a collective process over time, it emanates from policy work in many different spheres of practice (Turnbull 2013; Colebatch 2006). Documents (protocol, minutes, etc.), if they exist at all in the CC today, were considered of minor value as they are very concise and hardly tap into the underlying normative values and the "puzzling" that may have occurred before an issue was settled. Thus, how individuals and actor groups contribute to the "puzzling" of "policy problems" is best captured through interviewing. Observations were not considered feasible, especially not in the case of problem framing among senior administrators and unit managers (as much of the puzzling is taking place informally or tacitly).

A topic guide was designed with key questions. Questions relevant to this paper were grouped into two sections: health technologies as problematic situations and HTAC as a solution. The first section focused on the informants' reflections on the on-going influx of health technologies into the Swedish health service, nationally and regionally, what factors affect the present decisions on technologies and what arguments are of decisive importance for settling the issues. In the second section, the informants were asked to reflect on the role of HTAC in the decision-making structure of the $\mathrm{CC}$, to what extent HTAC can fulfil its mission, and what may be problematic concerning HTAC's activities in accomplishing its mission. 
Each interview lasted approx. $60 \mathrm{~min}$ and was carried out at a location chosen by the informant. They were audiotaped and transcribed verbatim. Translation of the transcripts from Swedish to English was done by one of the authors (ACN). A thematic content analysis of the interviews was carried out in accordance with the "framework approach" offered by Ritchie et al. (2003). The framework facilitates good structure and making sense of generalised data, allowing evolved themes and issues introduced by the topic guide to be drawn upon. It permits iterative movement between data, analytical concepts and interpretation derived from them. The data analysis began with asking the question "what?" to try to ascertain what was going on and to familiarise with the data. Subsequently, recurring themes were identified by paraphrasing and a conceptual framework was then created, which covered both the recurring themes and the issues that were raised in the topic guide. Data were classified under the different themes related to each actor group, often the same data were classified under several themes, and then grouped under a higher order of categories. The aim was to retain the expressions that originated from the informants. The interview texts were read again to reflect and ensure that they corresponded to the analysis. Recapitulating the material was also a way of seeing if the informants within each actor group had conflicting values or understandings. This is nothing unusual; rather it can highlight the different problem frames and the handling of different problem frames that exist both within and between the actor groups. The whole process was characterised by an interpretive approach, where the attempt was to understand the underlying accounts of their stories; what did they do, how did they do it and what was the meaning behind it? (Yanow 2000). The final phases involved finding patterns and making sense of the findings, the literature and the theoretical aspects in order to establish wider applications of the puzzling within varying problem frames.

\section{Findings}

The differences in puzzling and framing the problematic situation of health technologies and the experiences of the HTAC are highlighted in this section. The problem frames held by the members in the HTAC core group, the senior administrators, the members of the extended HTAC and finally the unit managers, will be accounted for.

\section{Problem frames and health technologies}




\section{The problem frames held by the members in the HTAC core group}

According to the members in the HTAC core group, it is common knowledge that Swedish healthcare has been active in utilising new innovations, but their introduction has been unstructured. New technologies are introduced in many different ways. Not least the introduction is dependent on the type of technology, where (a) pharmaceuticals are more controlled and regulated, while (b) non-pharmaceuticals are on the whole less controlled. Undoubtedly, directions originating at national level, together with the work by professional groups, have an impact on a more systematic view of new technologies. Notwithstanding, the need for a coherent national policy on the introduction of technology was emphasised.

Furthermore, the new era of the "information society" has decreased the role of experts, a result of better access to information for patients and lobbying groups, which is regarded as positive by the members in the HTAC core group. Although knowledge concerning the evaluation of the information does not automatically follow access to it, especially not as on many occasions there are interest groups, such as the pharmaceutical industry, behind innovations and information.

The introduction of new innovations is held to be a controversial matter since it relates to: how good the evidence is; who is responsible, i.e. tension between the clinicians' discretion and other actors who have opinions on how the clinicians should act; prestige, not only for the medical professionals but also for managers and politicians; keeping the best medical professionals in the organisation; the aspect of money, since innovations can imply new business; which treatments should be substituted or abolished. The latter encompasses that there can be differences in the use of technology between different professionals and specialists, which sometimes creates tension, especially if the consequence is that personnel face the risk of losing their current position. Another aspect is that the process covers different understandings of how rapidly technology should be adopted:

There is achievement in being early. (I10)

As an enthusiastic specialist you always want to have 'a new car' - but is it worth investing 30 million [SEK, equivalent to approx. 3 million Euro] on an expensive device just to keep up with development? (I11) 
Investments in "heavy devices" and new pharmaceuticals often attract a lot of attention since they have a significant direct influence on the CC's budget, while innovations related to the rigid traditional roles of medical doctors are more difficult to introduce.

In the view of the HTAC core members, problems related to the introduction of new technologies occur if innovations displace more effective technology; if an innovation is valuable to the patient but regarded as too costly for the $\mathrm{CC}$ 's budget; if there are, for example, no clear decision procedures or structures to claim more resources; if the introduction is too unsystematic, where technologies are introduced or replaced in a random manner; if old technologies are not abolished. All these aspects relate to a "collective problem" regarding the misuse of resources.

The introduction of new technologies was regarded as an unstructured process. As the CC is a political body, it was considered important that the professionals, the administrators and the politicians had opportunities to influence it. In principle, the introduction of all new technology to the $\mathrm{CC}$ ought to be based on evidence or some kind of "wellgrounded knowledge', otherwise it should be classified as an object for scientific research. However, the members emphasised that a large part of technology could not be assessed based on the criteria used in randomised controlled trials.

\section{The problem frames held by the senior administrators}

The senior administrators point out that new technologies were introduced into the healthcare organisation in several ways. Commonly, adaptation of new innovation was driven by enthusiastic professionals. The professionals were also deeply involved in research and the regeneration of new knowledge by designing new scientific studies that would affect clinical practice.

The process could also be driven externally by private companies, a situation in which the CC played "a dual role". An example that illustrated this was the establishment of the "innovation funnel", which aimed at providing a basis for innovation structures by identifying new ideas that could materialise in collaboration with the medical-technology industry and could ultimately result in an innovation adopted into clinical practice in the CC. 
As part of this project, the industry would come into close contact with the professionals in the CC.

The administrators identified four types of problems or risks concerning the introduction of new technology. Firstly, that the professionally driven introduction and adoption often moved rapidly, which ultimately resulted in costs that were too high. This could imply that the clinical unit concerned, or the $\mathrm{CC}$ as a whole, was not prepared for unexpected costs and lacked the procedures to allocate or reallocate resources to cover these new costs. In this case, the introduction of new technology was not coordinated with activities in the rest of the CC. Secondly, if technology was introduced in the wrong phase of its development and diffusion curve, i.e. at a time when the new technology was not fully developed, not yet assessed, but leading the field. If at this point new, more cost-effective innovations were to be introduced, they could totally expel the former technology. As a result the health service would be in possession of unusable technology, at least for its initially intended purpose.1 Thirdly, new technology that implied big investments and extreme unforeseen costs, but where there was little knowledge of the effects, such as, for example, new cancer drugs with minimal improvement for the patient compared with the old treatments, but carrying heavy costs. Often there is limited knowledge of the risk and commonly the industry provides the products with evidence of short-term effects, but not those of the long term. Fourthly, the toughest part was not the introduction, but the removal of technology that was considered unnecessary, these "old technologies" often remained in place:

A study shows that $20-25 \%$ of all healthcare services provided can be unnecessary, lacking in function and in worst-case scenario, actually do harm to the patients. (I18)

In the view of the administrators, the $\mathrm{CC}$ should always strive to use new technologies that are evidence based, provide benefits for the patients and are cost-effective, and not fund technology for random or historical reasons. Nevertheless, the administrators emphasised the importance of $\mathrm{CC}$ involvement in research, not least to safeguard the interests of the university hospital: 
If we find out that there is not enough evidence for a new technology but where it's still strategically important, we demand that studies be set-up in parallel so that we may gather more evidence. (I18)

As emphasised by the senior administrators in the $\mathrm{CC}$, the introduction of new technologies was for the most part positive and important; it implied improvement for the patient, for the $\mathrm{CC}$ and, in the long run, for the whole of society.

\section{The problem frames held by the members in the extended HTAC}

The members in the extended HTAC held the view that the inflow of new information, and new innovation was continuously apparent for all the different healthcare fields. It was, therefore, considered difficult to get a complete and clear picture and, ultimately, to know how to implement and adopt it into clinical practice. Accordingly, the overall situation was gradually becoming more complicated as new innovations were constantly being introduced at an extremely rapid pace. Nevertheless, the view held by this actor group was that the information flow was important, not least since the work at a university hospital had to be at the cutting edge of current research.

Information on new technology was to a large extent driven by the interaction of professionals, either in the form of input from scientific conferences and/or exchange between colleagues. Technologies could also be introduced on a recommendation from national level, e.g. as in the case of National Guidelines from the NBHW. Occasionally, new technology could attract extended media attention and be socially and political sensitive, which could affect the adoption of a specific technology, e.g. mammography or screening for abdominalaorta aneurysm. As emphasised, it was important to be aware that adoption of a technology could have negative consequences and expose patients to risks, e.g. as in the case of screening exposing the patients to too much radiation. As emphasised by the members, new innovations and technologies bore a high correlation to ethical aspects that had to be considered.

\section{The problem frames held by unit mangers}

According to the unit managers, new technologies were introduced into healthcare in different ways depending not only on the type of technology but also on the specific conditions in the 
unit concerned. Commonly, technologies were introduced through professional networks, often related to scientific conferences.

Many units had sites in their organisational structure where co-workers could discuss the introduction and use of new technology, most often in regular meetings. Though, the formality of these differed widely depending on whether the unit was handling highly advanced healthcare, was at the forefront of a research project, was part of primary healthcare or was a minor clinic. Another important factor affecting how new technology was regarded, was that the $\mathrm{CC}$ had a university hospital:

You have to use technologies that are evidence based, but at a university hospital you are obliged to create knowledge and evidence in research. (I7)

In units at the university hospital, it was commonly the professors who decided if a particular technology should be further considered, and subsequently established groups for this purpose. Other units, which were cooperating with the university, organised special reference groups, where staff belonging to the university conveyed knowledge about new findings and where the units enabled access to research projects directly influencing the clinical practices at those units. In primary healthcare, the situation was different, as new technologies were usually introduced under the influence of hospital specialists. Minor clinics differed from larger clinics and clinics at the forefront of research as the introduction of technology came late in the diffusion process; thus, the technology had generally been evaluated. Several units had specially appointed posts with the task of monitoring the research field and conveying knowledge to other co-workers. Medical students could also introduce new forms of knowledge when they were undergoing their practical education. New technology was also introduced via the medical-technology industry, either the companies made direct contact with the clinics and demonstrated their products or the professionals spotted technologies and actively made contact with the companies. Another way of getting information on new technology was through the National Guidelines produced by the NBHW.

It was also regarded as important to maintain the competence within the unit, especially when one unit had to compete with another because the results were made public in national comparisons, as highlighted by one unit manager: 
It's important to legitimate that we have the knowledge to use new technologies, for the citizens but also for colleagues and other professionals. (I3)

Aspects that were considered important when introducing new technologies were the patient perspective; benefits for the patient; the evidence base; risks; ethical consequences; and costeffectiveness. Personal prestige was considered:

The industry's great influence on healthcare can be frightening, both pharma and med-tech. These actors are performing with great enthusiasm and with extensive means. It's not always that they [clinicians] are critical enough, instead they easily fall for something that is a bit exciting, they get seduced by the opportunity to be someone internationally, to be an early expert on a technology. It can be that they are not as critical as they should be. (I7)

Many unit managers explained that they encouraged co-workers to initiate more research if the evidence regarding a technology had proven to be too limited. It was regarded as one way of preventing the use of technology without evaluation. As one unit manager emphasised, one must consider the alternative:

For example open surgery, what are the risks in performing it openly or performing it with a catheter? What are the risks for patients that are severely ill? What are the long-term effects? Is there any evidence? You have to weigh different aspects. (I7)

New technologies could imply increased costs for a unit but could, on the other hand, reduce costs for other units. Though resources were rarely reallocated to the unit that was responsible for the new treatment. Technologies that could be harmful for patients were not an option. In tough ethical cases, e.g. those that concerned life or death, treatments could be given in consideration of other indications than in a normal case. Such treatments were always provided, while in dialogue with the patient. In one such case, a unit had looked for support from the NBHW in order to see if there were reasonable arguments behind such a decision.

The introduction of new technologies could also spark off clashes between different cultures within the healthcare organisation, for example, when different professionals or specialists 
had diverse views on a specific technology. Those working close to patients could have one view, which differed from those working in intensive care, for example, catheter valves, where the former saw the benefits of the technology and the latter encountered patients when the use of the technology had failed. Guidance in this context was commonly searched for at the national level. New technologies could also be regarded as a threat to professionals' identity, e.g. when a professional felt safe using established technology.

Occasionally, strong economic incentives coming from national or regional levels to adopt a specific technology could endanger the balance in the unit's kit of interventions, as some other technologies became displaced, especially if established technologies were regarded as more important.

\section{Experiences of the HTAC and the puzzling solution}

\section{The problem frames held by the members in the HTAC core group}

According to the members in the HTAC core group the influx of new technology in the CC was occurring without much control. The intention behind the establishment of the HTAC was to make the clinicians aware of an unsatisfactory situation and emphasise the importance of using evidence when making decisions on new technologies. The intention was to find experts from the $\mathrm{CC}$ and the university who had a scientific approach to the use of the technologies. In that way, the HTAC should have a scientific service-functioning role, without any decision-making power, working scientifically and independently in order to "rub down tendentious interpretations". The HTAC should make evidence-based recommendations as to whether or not technology ought to be introduced in the clinical units as well as to the managers and politicians.

However, from the point of view of the members, there were several problems experienced with regard to the operation of the HTAC. Firstly, its position in the CC organisation was too vaguely defined in the political, management and clinical spheres:

We haven't found our role. We're not sure what the senior managers in the CC want us to do. We haven't found a working procedure that is reasonable in relation to the amount of people who are working in the HTAC. (I11) 
The HTAC did not receive much attention from the senior administrators who were responsible for the allocation of resources to the health service. They did not ask for a recommendation before decisions on major investments in new technology, nor did they use the HTAC in discussions with the clinical units.

Secondly, the HTAC was seldom used in a systematic way, e.g. too few cases were initiated by the units. Cases had either been initiated by single individuals wanting to use this body as a conduit to receive money or resources or where members in the HTAC had identified a case. In general, the CCs used other structures for systematising evidence related to technologies, e.g. the professionals used their national and international professional networks. One problem experienced was that it was too risky for clinicians to pass on a case to the HTAC. It could become a "lose-lose situation"; either they received a negative response or a positive one, but probably without any extra financial resources. Therefore, there should have been financial incentives for the units to pass issues on to the HTAC. Apart from this, there were difficulties for the HTAC to be involved at the right time in the adoption process, as the technology was either in the research phase or the adoption had already gone too far. Some members in the core group expressed self-critical views that they themselves should have been more effective in promoting their cause by participating in different types of meetings and communicating with the clinical units. Thus, lacking an obvious position in combination with a lack of incentives for the clinical units to use this body, the HTAC was rendered "pointless" and labelled a "lame duck".

Still, the view among the members was that the HTAC had been valuable in different ways. Firstly, in the case of controversies, when the evidence was unclear and where there were internal tensions regarding the value and consequences of an innovation. The example experienced was a totally new innovation where arguments for an introduction had been proposed, but the evidence base was far from clear. The HTAC recommended that more research had to be done and that an introduction was not motivated. This case had the potential to be controversial, not least since it incorporated values, competing interests and tensions among the clinicians, but became defused:

We had one such case. And we made a judgement. What I know from those involved is that it was valuable that the process was transparent, that different actors had the possibility a couple of times to give voice to their opinions. Even 
if the decision that was made, based on our judgement, was not of benefit to one party in the controversy. (I11)

Secondly, the HTAC had proved to have an important role concerning technologies related to big investments. Thirdly, the HTAC was important and played a supportive role on other occasions in the $\mathrm{CC}$, such as when a comprehensive resource-allocation process was carried out.

According to the members, there is a need to find a better structure for handling issues related to the introduction and use of technologies, and therefore, a need for a body that has more control over the issues. There should be strong incentives among the clinical units, to use the service before new technology is introduced. It was also regarded as important to have faster procedures when judging technology, including clear awareness of which type of documents had to be produced before a judgement. Therefore, such a body had to be equipped with greater capacity to "set the standard" for the working process and the outcome, which would demand several scientifically trained people.

\section{The problem frames held by the senior administrators}

The HTAC was established to create a structure for managing the flow of new technologies since their adoption was generally related to large investments. Moreover, the economical situation for the $\mathrm{CC}$ was much worse than previously, which implied that the professionals' discretion in introducing newtechnologies should be limited; introduction of innovations had to be done within the economical frames. From their perspective, there was a need for controlled and coordinated introduction of new technology, while also in principle supporting the use of new innovations. According to them, the whole $\mathrm{CC}$ organisation had a mind to development:

We always have to get better and improve our way of working to get better results. (I19)

In the view of this actor group, the HTAC was established as a body that could support decision-makers and its task was to assess the evidence base for new innovations, technologies, methods and new ways of working. The support was not only targeted at senior administrators but also at the politicians, regarding what technologies should be funded in the 
CC. Some technologies have always been politically sensitive in Sweden. In such a climate, the HTAC was of importance since the politicians were living for every new election and needed public popularity. One example given was mammography where weak evidence existed for the national comprehensive screening programme, which encompassed the screening of every women aged 40-75 every second year, in terms of cost-effectiveness. But it was too politically sensitive to even discuss whether the programme should be less comprehensive. Another task was to examine whether old technologies could be earmarked for disinvestment. The HTAC consisted of "enthusiastic" people, who had experience of making assessments in a systematic and evidence-based way. The idea was to have the HTAC as a neutral body without any power to make decisions but to undertake evaluations, collect evidence about technologies and make recommendations.

The view held by the administrators was that the HTAC was important as a producer and assessor of systematic knowledge reviews. This body had given the healthcare management a more systematic way of approaching new investments in technology and made the politicians feel more secure in issues that occasionally were highly politically sensitive. However, one senior administrator experienced that the HTAC was rarely used:

I know that at the senior management level of the $\mathrm{CC}$, when we are handling some difficult issues, the option did not occur to them to let the HTAC assess the issue. And it takes too long to pass issues to the HTAC. (I19).

The view held by the senior administrators was that only when the introduction of new technology was related to high costs should the senior management of the CC (administrators and politicians) be involved. In all other cases, introduction should be decided in the units since "they were the experts". Hence, one way of controlling the introduction of new technology was to bring the various clinical unit managers together in a joint discussion, where unit managers had to explain for each other the limits in their budget and why they should have more resources.

\section{The problem frames held by the members in the extended HTAC}

The members in the extended HTAC expressed that the aim of the HTAC was to create a forum where different new technologies could be evaluated based on patient benefit, costefficiency, etc. However, few cases were handled by the HTAC in an extended process. 
Instead, many cases by-passed the HTAC as the clinical units were using regional, national and international guidance to support their decisions to adopt technology:

This area is complex, it is diversified, so many decisions about the introductions are taken...some guidelines are drawn up in other constellations, maybe regional or nationally, and then you by-pass the HTAC. (I16)

The HTAC was seen as an "old-fashioned"' body that could not relate to the needs of modern healthcare with all its complexity. Accordingly, members of the extended HTAC found it impossible for this type of mechanism to handle all types of issues that emerged at the various clinical units, between various clinics and between different healthcare areas:

The HTAC became like a little isolated island, a few issues passed but most issues were handled in other settings with the same procedure and requirements as the HTAC had. (I16)

The view held by the members of the extended HTAC was that this body acted in a professional manner, but did not have a good grip of its role. A better solution would be to use structures that already existed in the CC. Introduction of new technology was an ongoing process, and the degree of complexity was not reducing but increasing.

\section{The problem frames held by the unit mangers}

Many unit managers had limited knowledge about the role of the HTAC in the CC, its capacity and possible support. Unit managers who had some knowledge about theHTACliked the concept where a body should assess the cost utility of technologies and give a judgment on how to handle adoption or disinvestment. To use the HTAC could in certain cases be favourable in the dialogue with senior management at the $\mathrm{CC}$ since it could imply that technology had better chances of being prioritised and thus receive funding. This would be true particularly if the HTAC had the supported funding of technology that was related to high costs. Still, the view held by the unit managers was that the HTAC took far too long to examine technology, which became problematic, as these cases were often considered urgent. Moreover, the HTAC was regarded as having limited knowledge in all clinical areas. Thus, inmost cases, itwas not seen as an option. In order to find support to handle difficult issues when new technologies were introduced, the professionals and unitmanagerswere using 
different channels and support structures. They could differ depending on what unit and case was on the agenda. Examples of support structures were various local professional organised groups, national and regional professional networks, research networks, the ethical committee in the $\mathrm{CC}$, the $\mathrm{R} \& \mathrm{D}$ unit in the $\mathrm{CC}$, the Committee of Pharmaceuticals in the CC, various departments in the university and the NBHW. Therefore, it was considered important for the HTAC to inform the unit managers as towhy they should pass on cases to this panel. The HTAC was, therefore, not considered as the obvious option, nor the solution of an understood problem related to the introduction of new technologies.

\section{The puzzling problem and its immanent solution}

In this section, we will summarise what the actor groups (a) understood as problematic situations in the context of new technologies, (b) expressed as their experience of the HTAC and (c) expressed as the preferred policy style related to the puzzled problem of new technologies. The actor groups held different frames on the policy problem related to the introduction of health technology. The actor groups studied, also had various experiences of the HTAC, and for some of the actor groups, this was related to the preferred policy style in handling the influx of new technologies. The findings with regard to the different problem frames held by the four actor groups are summarised in Table 1.

Table 1 The problematic situation(s), experiences of HTAC and the preferred policy style - the problem frames held by the informants.

\begin{tabular}{|c|c|c|c|}
\hline Actor group & $\begin{array}{l}\text { Problematic situation(s) } \\
\text { related to the introduction } \\
\text { of HT }\end{array}$ & Experiences of HTAC & $\begin{array}{l}\text { Preferred policy style } \\
\text { of the puzzled } \\
\text { problem }\end{array}$ \\
\hline $\begin{array}{l}\text { The members } \\
\text { in HTAC core } \\
\text { group }\end{array}$ & $\begin{array}{l}\text { Lack of knowledge and } \\
\text { evidence on, e.g. cost- } \\
\text { effectiveness and value for } \\
\text { money. } \\
\text { Better coordination is } \\
\text { needed nationally. } \\
\text { Need to control costs. }\end{array}$ & $\begin{array}{l}\text { Not used to its full capacity. } \\
\text { Particularly useful when: } \\
\text { internal tensions; big } \\
\text { investments; major resource } \\
\text { allocation in CC. }\end{array}$ & $\begin{array}{l}\text { As experienced by } \\
\text { HTAC but } \\
\text { supplemented by } \\
\text { economic incentives } \\
\text { and dialogue with } \\
\text { clinical management. } \\
\text { Better capacity but } \\
\text { strictly scientific } \\
\text { profile. }\end{array}$ \\
\hline $\begin{array}{l}\text { The senior } \\
\text { administrators }\end{array}$ & $\begin{array}{l}\text { Need to secure knowledge } \\
\text { and evidence for new } \\
\text { technologies, if more } \\
\text { research is not needed. } \\
\text { Inability to get rid of old } \\
\text { technologies. } \\
\text { Need to control costs. } \\
\text { Inability to coordinate }\end{array}$ & $\begin{array}{l}\text { Useful evaluations. } \\
\text { Useful support for senior } \\
\text { management. } \\
\text { Useful if the case is } \\
\text { politically sensitive. }\end{array}$ & $\begin{array}{l}\text { As experienced by } \\
\text { HTAC but } \\
\text { supplemented by } \\
\text { economic incentives } \\
\text { and dialogue with } \\
\text { clinical management. } \\
\text { Also more on } \\
\text { disinvestment of old }\end{array}$ \\
\hline
\end{tabular}


introduction within $\mathrm{CC}$

The members Need to consider research in extended HTAC

knowledge, evidence and

patient safety.
The scope of new

knowledge.

Flow of new information.

Consequences that can be

politically sensitive.

The clinical unit managers
Flow of knowledge and new information.

Being expert in this massive flow of information.

Use of economic incentives

to affect adoption.

Different units, different

technologies, generate

different problems.

Fostering research to keep

competence in the unit.
Highly qualified body but old-fashioned in its working. Should be integrated into other processes in the CC.

Limited knowledge on HTAC.

Not an obvious solution. Could be useful only on certain occasions. technologies.

Use structures that already exist in order to obtain support to regulate the flow of information and new knowledge.

Use already established professional and research networks related to own problem frame.

Table 1 shows that all actor groups emphasised knowledge and evidence as important when puzzling problems related to the influx of new technologies. However, the actor groups had various understandings on how knowledge and evidence was problematic. In other words, they gave different meanings to a "problem" related to knowledge and evidence. Evidence was highlighted, but appeared not to be easily translated (Freeman 2009), where all actor groups were using the term, but were giving it different meanings and problem frames. For example, when referring to evidence as a problem, some of the actors would suggest that " a lack of evidence" was the problem, while other actors related to a situation where the available information was not underpinned by "good" evidence or that the introduction of new technology had been founded on limited evidence.

Thus to a large extent, the informants in the four actor groups had different problem frames. Most noticeably, the unit managers' views of problems related to the introduction of new technology, diverged markedly from the problem frames perceived by the members in the HTAC core group.

It was apparent that the members of the HTAC core group and the senior administrators in the $\mathrm{CC}$ perceived that the essential problem and its solution related mainly to controlling future costs in the healthcare system. The unit managers and the members in the extended HTAC, on 
the other hand, perceived the problem as related more to controlling the scope of new information and the inflow of new knowledge.

Informants, mainly among the unit managers, but also in the other categories, stressed that they could see no reason why somebody should turn to the HTAC to get support, except in exceptional circumstances. Senior administrators and members of the HTAC core group found the body useful, in particular, when some kind of conflict or tension existed concerning a certain case.

Examples given by the unit managers showed that they often preferred other solutions to the problems they perceived as related to the introduction of new health technologies. In such cases, the solution, and thus its related policy style, did not gain support from the HTAC. Instead, they identified solutions closer to the work of the unit, for example, involving and consulting professional reference groups and other professional and scientific networking groups.

Consequently, from the perspective of the senior administrators and the members in the core group, the HTAC was closely integrated within a problem frame where the use of evidence, in other words EBP, was seen as a promising solution, although the core group was the most explicit defender of science. However, when the same two actor groups referred to their experiences in later years, the HTAC contained less agreement on norms and values, but the role of evidence and the value of cost-effectiveness were still considered highly relevant. In contrast, the HTAC was partly invisible to the unit managers. The experience of the members in the extended HTAC was that the HTAC was not embedded in the ordinary decisionmaking structures. Thus, the latter actor group referred to a policy style that could, to a large extent, embrace different puzzled problems. They were more open to using the formal structure of the $\mathrm{CC}$ and thus more open to regulation, although not necessarily through a body such as the HTAC.

\section{Discussion and conclusion}

Our intention has been to explore problem frames associated with the handling of new health technology in the context of a particular institutional solution, as represented by the advisory body HTAC, at the regional level in Sweden. In this section, we take a closer look at the shaping of policy as an interplay between puzzling, power and participation. 
Our case illustrates the puzzling of a policy problem where no collective problem frame exists among the various actor groups on how to go forward, except for assumptions that medical innovations are fundamentally positive, that clinical efficacy, including the benefit for the patient, is central and that evidence and knowledge are extremely important in this context. Also that further research on new innovations is relevant, especially as the CC operates a university hospital. Still, it is clear that the "interpreted contexts" and institutional norms for discussion and debate vary from actor to actor, which causes them to approach the issue from different perspectives, and is apparent when actor groups explicate what policy style they prefer. Our example illustrates how the problem frame is dependent on who is participating and who is not participating in the puzzling in a particular institutional context. It is obvious that the $\mathrm{CC}$ is not homogenous with regard to problem frames and that different domains of practice exist in parallel. This is demonstrated by the similar problem frames emphasising cost control held by the members in the core group of the HTAC and the senior administrators in the CC, and in parallel, by the similar frames concerning the control of the inflow of new knowledge held by the members in the extended HTAC and by the unit managers. They were participating and deliberating in the same type of network, and with each other. Although members in the extended HTAC also participated in the collective puzzling offered by HTAC, which implied that they were more open to regulation.

We can see that there are two types of definition or truths concerning the problem, which relate to the current distribution of power in the $\mathrm{CC}$ : (a) the assumption that the problem concerns future costs and (b) that the problem is associated with a need to be updated in the increasing flow of information and knowledge. No one of these truths, presented by the actors, is more or less correct than any other; however, the implications vary depending on power. The impact depends on who has the power to define the problem and what rationale they subscribe to. The senior administrators are operating at the level where those in power define the problem in terms of cost control. The members in the HTAC core group are associated with this organisational level and its policy network. And conversely, at the organisational level where the clinical unit managers are operating, the power to define the problem rests with the professionals. As Hoppe (2010) explains, puzzling, participation and power are interlinked and are, therefore, difficult to clearly separate in an empirical study. However, it is reasonable to accept that the policy issue and thus the policy problem is related 
to collective sense-making, which revisits the question of who is allowed to participate in that collective. As Colebatch frames it:

How a policy is perceived depends on who is sitting around the table and who is sitting around the table depends on how the problem is perceived. (Colebatch 2011).

Moreover, the question of how the policy problem is framed also depends on where the table is located, in our case, the position of the HTAC in the CC organisation. In other words, the meaning behind the problem relates to the dominating problem frame of the actors in the core group of the HTAC and the senior administrators. Drawing on the empirical case, we observe that a collective solution did not ensue, since the policy style preferred by the senior administrators did not coincide with that of the unit managers. In that sense, the empirical case illustrates a "wrong-problem problem", i.e. a problematic situation is handled that is not within the problem frames of others. The critical aspect concerns to whom the power to define the rationality belongs, which in our case is not obvious as both the senior administrators and the professionals control important means within the CC organisation (Lin 2003). The former group control the economic resources on behalf of the politicians and the latter group are in control of their expertise. The setting up of the body HTAC followed a scientific rationality, dominated by positivist science. This is traditionally a strong rationality within the healthcare sector. Hence, it is a solution associated with the search for the "best evidence'. However, even if the quest for better evidence and science was more or less embedded in the problem frame and the preferred policy style among all actor groups, there were different meanings in their sense-making. For the senior administrator and the members in the HTAC core group, the intention was to use science for the purposes of control and evaluation, while the unit managers saw it as a driving force and thus a means for safeguarding and expanding their professional territory. Accordingly, we can see that, in line with Turnbull (2013:124), all actor groups identified a well-known solution and a policy style following their own practice and strategic goals. For the senior administrators and the HTAC core group, the HTAC represented, in line with Hisschemöller and Hoppe (1996), "the only one" solution that seemed doable as it was related to their institutionalised norms of how to handle this kind of problematic situation. Though it is salient that the problem, as framed by all actor groups, was not solely a matter of evidence. The study also shows the reordering of power (Vink et al. 2012; Hall 1993), since the allocation of power in the CC formed the process of puzzling over 
what was regarded as the appropriate problem frames, thus cementing the existing power structure in the CC. Following Turnbull (2013), we can see that the ambiguous search for an all-embracing solution in a complex knowledge-intensive policy field, came to be dominated by one problem frame where the questioning was forgotten as a result of strong forms of answering.

\section{Acknowledgments}

The article is based on research supported by the Vinnva ${ }^{\circ}$ rd Research Program Grant no. A2008-017 "INTEGRAL" and by the County Council of O " stergo"tland, Sweden.The Informants are acknowledged with gratitude. The authors also thank the organizers and the participants at the panel "Evidence and Meaning in Policy Practice", at the Interpretive Policy Analysis Conference 2012, in Tilburg, as well as the three anonymous reviewers for helpful comments and suggestions on earlier drafts.

\section{References}

Bijker, W. E., Bal, R., \& Hendrik, R. (2009). The paradox of scientific authority: The role of scientific advice in democracies. Cambridge: The MIT Press.

Blumer, H. (1971). Social problems as collective behavior. Social Problems, 18, 298-306.

CCO [County Council of Östergotland]. (2011). Verksamhetsbera“ttelse Metodra ${ }^{\circ}$ det 20092010. fFebruari 2011. Linköping: Landstinget i Östergötland.

Colebatch, H. K. (2006). What work makes policy? Policy Sciences, 39(40), 309-321.

Colebatch, H. (2011). Challenge and development: The emerging understanding of policy work. Politika misao, 48(5), 11-24.

Dewulf, A., Craps, M., Bouwen, R., Taillieu, T., \& Pahl-Wost, C. (2005). Integrated management of natural resources: Dealing with ambiguous issues, multiple actors and diverging frames. Water Science and Technology, 52(6), 115-124.

Freeman, R. (2007). Epistemological bricolage: How practitioners make sense of learning. Administration and Society, 39(40), 476-496.

Freeman, R. (2009). What is 'translation'? Evidence and Policy, 5(4), 429-447.

Gillman, B. (2000). The research interview. London: Continuum.

Greenhalgh, T., \& Russell, J. (2009). Evidence-based policymaking a critique. Perspectives in Biology and Medicine, 52(2), 304-318. 
Hall, P. (1993). Policy paradigms, social learning, and the state: The case of economic policymaking in Britain. Comparative Politics, 25(3), 275-296.

Heclo, H. (1974/2010). Modern social politics in Britain and Sweden. From relief to income maintenance. New Haven: Yale University Press. Republished 2010 by ECPR.

Hisschemöller, M., \& Hoppe, R. (1996). Coping with intractable controversies: The case for problem structuring in policy design and analysis. Knowledge for Policy, 4(8), 40-60.

Hoppe, R. (2010). The governance of problems: Puzzling, powering and participation. Bristol: The policy press.

Howlett, M. (2002). Understanding national administrative cultures and their impact upon administrative reform: A neo-institutional model and analysis. Policy, Organisation and Society, 21(1), 1-24.

Klein, R. (2003). Evidence and policy: Interpreting the Delphic oracle. Journal of the Royal Society of Medicine, 96(9), 429-431.

Lehoux, P., Denis, J. L., Rock, M., Hivon, M., \& Tailliez, S. (2010). How medical specialists appraise three controversial health innovations: Scientific, clinical and social arguments. Sociology of Health \& Illness, 32(1), 123-139.

Lin, V. (2003). Competing rationalities: Evidence-based health policy. In V. Lin, B. Gibson (Ed.), Evidencebased health policy: Problems and possibilities (pp. 3-17). Melbourne: Oxford University Press.

Majone, G. (1989). Evidence, argument, and persuasion in the policy process. New Haven: Yale University Press.

Moran, M. (1995). Three faces of the health care state. Journal of Health Politics, Policy and Law, 20(3), 767-785.

Nedlund, A. C. (2012). Designing for legitimacy: Policy work and the art of juggling when setting limits in health care. Linköping: Linköping University Electronic Press.

Noordegraaf, M. (2010). Academic accounts of policy experiences. In H. K. Colebatch, R. Hoppe, \& M. Noordegraaf (Eds.), Working for policy. Amsterdam: Amsterdam University Press.

Packer, C., Simpson, S., \& Stevens, A. (2006). International diffusion of new health technologies: A ten country analysis of six health technologies. International Journal of Technology Assessment in Health Care, 22(4), 419-428.

Patton, M. Q. (2002). Qualitative research and evaluation methods. London: Sage.

Rein, M., \& Schön, D. (1996). Frame-critical policy analysis and frame-reflective policy practice. Knowledge, Technology and Policy, 9(1), 85-104. 
Richardson, J., Gustafsson, G., \& Jordan, G. (1982). The concept of policy style. In J. Richardson (Ed.), Policy styles in Western Europe. London: Allen and Unwin.

Ritchie, J., \& Lewis, J. (2003). Qualitative research practise: A guide for social science students and researchers. London: Sage.

Ritchie, J., Spencer, L., \& O’Connor, W. (2003). Carrying out qualitative analysis. In J. Ritchie \& J. Lewis (Eds.), Qualitative research practise: A guide for social science students and researchers. London: Sage.

Russell, J., Greenhalgh, T., Byrne, E., \& McDonnell, J. (2008). Recognizing rhetoric in health care policy analysis. Journal of Health Services Research Policy, 13(1), 40-46.

Schneider, A., \& Ingram, H. (1997). Policy design for democracy. Lawrence: University Press of Kansas.

Schön, D. A., \& Rein, M. (1994). Frame reflection: Toward the resolution of intractable policy controversies. New York: BasicBooks.

Stone, D. A. (2002). Policy paradox: The art of political decision making. New York: Norton. Syrett, K. (2003). A technocratic fix to the "legitimacy problem"? The Blair government and health care rationing in the United Kingdom. Journal of Health Politics, Policy and Law 28(4), 715-746.

Turnbull, N. (2013). The questioning theory of policy practice: Outline of an integrated analytical framework. Critical Policy Studies, 7(2), 115-131.

Vink, M. J., Boezeman, D., Dewulf, A., \& Termeer, C. J. A. M. (2012). Changing climate, changing frames. Dutch water policy frame developments in the context of a rise and fall of attention to climate change. Environmental Science and Policy, 30, 90-101.

Visser, J., Hemerijck, A. (1997). A Dutch miracle. Job growth, welfare reform and corporatism in the Netherlands. Amsterdam: Amsterdam University Press.

Wagenaar, H. (2004). "Knowing"' the rules: administrative work as practice. Public Administration Review, 64(6), 643-658.

Weick, K. E. (1995). Sensemaking in organizations. Thousand Oaks: Sage.

Wesselink, A., \& Hoppe, R. (2011). If post-normal science is the solution, what is the problem?: The politics of activist environmental science. Science, Technology and Human Values, 36(3), 389-412.

Yanow, D. (2000). Conducting interpretive policy analysis. Thousand Oaks: Sage. 
